UCRI- 91968

PREPRINT

\title{
NUMERICAL S.TUIES OF \\ HIGH CURRENT BEAM COMPRESSION IN \\ HEAVY ION FUSION
}

\author{
J. W-K Mark \\ Lawrence Livermore National Laboratory \\ Livermore, CA
}

J. Bisognano and E. P. Lee

Lawrence Berkeley Laboratory

Berkeley, CA.

This paper was prepared for submittal to

1985 Particle Accelerator Confererce/TRIUMF

held in Vancouver, B.C., May 13-16, 1985

May 10,1985

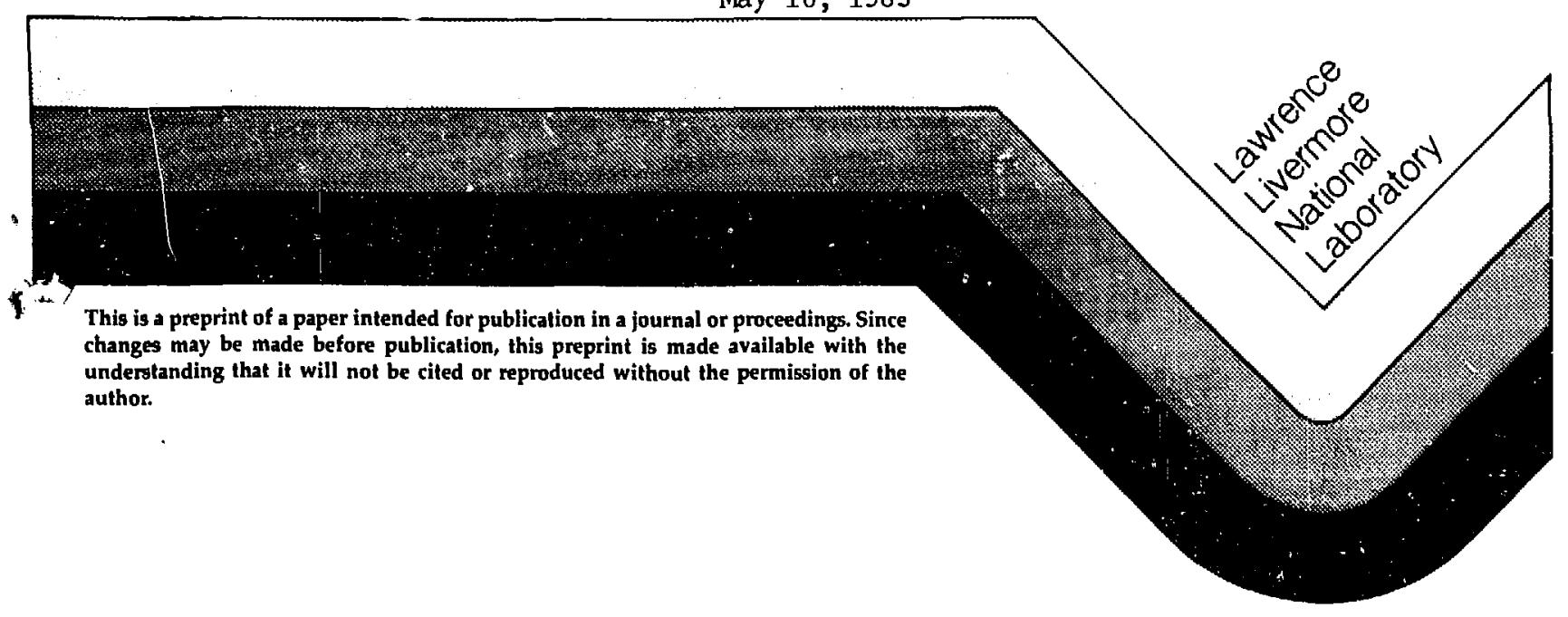


NUMERICAL STUDIES OF HIGH CURRENT BEAM COMPRESSION

IN HEAVY ION FUSION*

J. Bi bognano and E. P. Lee

Lawrence Berkeley Laboratory

Berkeley, California 94702

$95 / 3 \quad$ UCRL- -91968

James W-K. Mark

Lawrence Livermore National Laboratory 75 ,

DE85 011874

$P, 0$. Box 808

Livermore, California 94550

The process of longitudinal compression of a drifting heavy ion pulse to be used as an ICF driver is examined with the aid of particle simulation. Space charge forces play a vital role in halting compression before the final focus lens gystem is reached. This must take place with minimal growth of transverse emittance and momentum spread. Of particular concern are the distortion of longitudinal phase space by the rounded transverse profile of the longitudinal self-electric field.

For application as an ICE reactor driver, a heavy-ion beam pulse must be longitudinally compressed by 1 to 2 orders of magnitude to achieve the peak power required to ignite a target. 1 This process, among others, will be tested in a facility known as the "High-Temperature Experiment"2-6 in heavy-ion fusion. Beam compression is a critical element of an accelerator for heavy-ion fusion; it occurs primarily after the main phase of acceleration and before final focus onto target.

Here ve examine the compression of a drifting heavy-ion pulse with the aid of particle simulations. We describe initial theoretical results for an in-principle solution to this problem. Further refinements including integration into a complete driver system are necessary before the least costly solution can be chosen.

An accelerated beam pulse has finite extent in space and time. Beam compression is initiated by firing the accelerating modules so that the tail end of the beam moves faster than the head. The variation of velocity is a linear function of distance (messured from the center of the pulse), this differential velocity can be viewed as a velocity "tilt" in longitudinal $\left(z, v_{z}\right)$ phase space [see Fig. $1(a)$ ]. At the end of beam compression, the tilt is removed and the compression is halted (and even reversed) by the longitudinal spac-charge repulsion in the compressed beam bunch. (In the absence of finite space charge effecta, the free-streaming velocity differentials and longitudinal emittance would instead be the determining factor for minimum beam length). Of course, we would have to impose external fields on the compressed beam to keep it compressed for any length of time. In practice, the beam bunch will be sent through the final focus lens system and onto the target before auch expangion occurs. This entire process must be carefully controlled to produce the desired small spot on the fusion pellet. During compression, the transverse dimensions of the pulse must be controlled by alternating-gradient focusing.

*This work was supported by the Department of Energy Office of Energy Research under Contract No. DE-AC03-76SF00098 to Lawrence Berkeley

Laboratory, and also office of Inertial Fuaion under Contract No. W-7405-ENG-48 to Lawrence Livermore National Laboratory.
Apart from the decrease in pulse length, it is also necessary to observe the requirements on the final beam pulse necessary to focus it onto a target at a particular focal distance. of particular importance in the present context are second order chromatic aberrations which for rough illustrative purposes provide a condition

$$
r_{\text {spot }}>2\left(\frac{\Delta \mathrm{P}_{2}}{\mathrm{P}_{2}}\right)_{\text {lens }}\left(r_{\max }\right)_{\text {lens }} .
$$

Here $r_{\text {spot }}=0.1 \mathrm{~cm}$ is the envelope radius of the desired focal spot, $\left(r_{\text {max }}\right)_{\text {lens }}=10 \mathrm{~cm}$ is the envelope radius at the final focus lens, and $\Delta \mathrm{p}_{z} / \mathrm{p}_{\mathrm{z}}$ is the full width in the dispersion of $z$ momenta (accumulated from all sources) at final focus. These typical numbers imply that $\Delta \mathrm{P}_{\mathrm{z}} / \mathrm{Pz}_{\mathrm{z}}<0.01$.

A second condition is that the transverse emittance * wust be sufficiently small. To $l$ imit the effect of spherical aberrations in the final lens, the half-angle of the focal cone must satisfy

$$
\theta_{\mathrm{g}}<0.02 \mathrm{rad} \text {. }
$$

Using the emittance determined spot radius $r \geq c / \theta$, this translates into the condition $\varepsilon \leq 2 \times 10^{-3}$ cmrad, which applies after final compression.

A simplified analytic solution obtains if we adopt the model of a one-dimensional beam that has no longitudinal momentum spread $\Delta \mathrm{P}_{z}$ at any $z$ before beam compression. The space-charge self field of the beam bunch is approximated by the electric field

$$
E_{z}=-g \frac{\partial \lambda}{\partial z}
$$

where $A(z, t)$ is line charge denaity; and $g$ is a coupling applicable to long-wavelength disturbances. In this regime $g$ has the value

$$
g=\frac{1}{4 \pi E_{0}}\left(\log \frac{b^{2}}{a^{2}}+\frac{1}{2}\right) .
$$

In this idealized limit, the beam pulse obeys one-dimenaional fluid equations in $\lambda$ and $v_{z}$, where $v_{z}(z, t)$ is beam internal velocity. We can obtain an exact oolution with a parabolic longitudinal profile for $\lambda$

$$
\begin{aligned}
& x(z, t)=\frac{\lambda_{0} L_{0}}{L(t)}\left[1-4 \frac{(z-\bar{z})^{2}}{L^{2}(t)}\right], \\
& v_{z}(z, t)=\bar{v}+(z-\bar{z}) \frac{d}{d t} \ln L(t),
\end{aligned}
$$

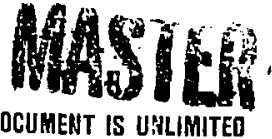


This simplified solution provides a useful guide to an in-principle solution of the besm compression process provided that it survives under the realistic, multidimensional enviroment of actual pulses. In the preveat case the conatant factor $g$ is replaced by a radius-dependent term characteriatic of actual beams, oo that particles at different radii $r$ are ected on by different longitudinal self-forces and experience different evolution, resulting in growth of $\triangle P_{z}$ at each point in the pulae.

An estimate that $g$ varies over $r$ by \pm 20 resulta in the evolution of phase pace $\left(z, v_{z}\right)$ and line denoity $\lambda(z, t)$ shown in Figs. 1 and 2 . These results were obtained using our one-dimengional particlesimulation code BLISS, which uses the field of: Eq. (3). Although actual transverse particle rotions average over actual opread of $g$ with radius, this one-dimensional medel assigns each particle a g-factor appropriate only to its initial position.

$A s$ expected, the initial momentum tilt $\left(\Delta \mathrm{p}_{\mathrm{z}} / \mathrm{p}_{z}\right)=$ 47 of Fig. I(a) is topped in Fig. l(c), but at the expense of some momentum spread $\Delta \mathrm{p}_{2} / \mathrm{P}_{z}$. The $\mathrm{sinr}$ ated problem corresponds to the situation typical of the High-Temperature Experiment, in which a $1.875 \mu \mathrm{C}$, 125-HeV beam of singly ionized sodium vill be compressed from a length of $10 \mathrm{~m}$ to a final length (according to our analytic model) of $1 \mathrm{~m}$. Since the model shows that opace-charge effects are important only in the last 2 m of compression, our simulation concentrates on thia phase.
We also used a swo-dimensional LLML version of the particle code MASR ${ }^{7}$ to repeat the onedinensional $s$ imulation, with resligtic varistion of 8 with $r$ automatically included in the force calculations. The initial momentum apread $\Delta \mathrm{p}_{2} / \mathrm{p}_{2} \propto 4 \mathrm{X}$ results in a final momentum spread $\triangle P_{z} / P_{2}<0.57$ in this $B$ imulation (Figs. 3 and 4 ). This final $\Delta \mathrm{P}_{z} / \mathrm{P}_{z}$ is comparable to that found for the one-dimensional simulation, with ito artificislly opread g-factor.

The two-dimensionsl ginulation again uges a 1.875- $\mathrm{C}, 125-\mathrm{HeV}$ beam of lia ${ }^{+}$ions. The beam radius has the value $a=1 \mathrm{~cm}$, and the perfectly conducting pipe has radius $b=2 \mathrm{~cm}$. The boundary conditions at $z+ \pm \infty$ are approsimated accurately by doubling the periodicity length of the simulation region in $z$, because the Green's function falls of $f$ exponentially. The transverse quadrupole focusing forces are approximated by the axially symetric radial electrie field

$$
E_{r}=-5.266 \times 10^{6} \frac{r}{b} v / m \text {. }
$$

A total of 46,751 particles are used on a $20 \times 512$ grid, representing a region $2 \mathrm{~cm} \times 2 \mathrm{~m}$ in the $I$ and $z$ directions, respectively. The inirisl line density $\lambda(z, 0)$ is made nearly parabolic by the superposition of 20 constant-charge-density and constant-radiuo $(r=a)$ components. Each such component is loaded with a Haxwellian velocity dietribution with

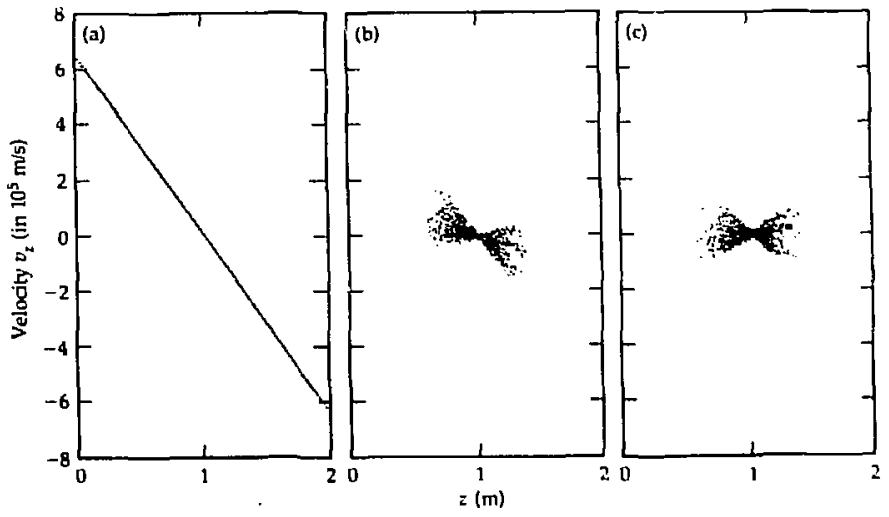

Fig. 1. The $\left(z, v_{z}\right)$ phase space of the l-D particle-code simulation (see text) at (a) $t=0$ (initial velocity $t i l t$ ), (b) $t=0.7 \mu \mathrm{g}$, (c) $t=1.5 \mu \mathrm{s}$ (finsl compressed state).

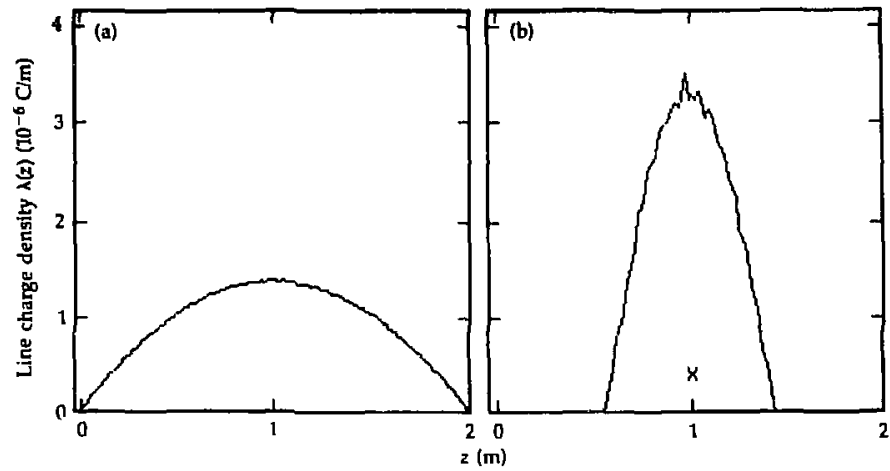

Fig. 2. Spatial $l$ ine densities $\lambda(z, t)$ of particles in the $1 \rightarrow 0$ simulation of Fig. 1 at $(a) t=0,(b) t=1.5 \mu \mathrm{s}$. 


$$
\bar{v}_{1}^{2}=\frac{2 i-1}{20}, \quad, i=1, \ldots, 20,
$$

where characterized the required $\overline{v_{1}^{2}}$ at $z=0$ for the parabolic diatribulios. Hote that $\overline{(2 i-i) / 20}-1$, o that londing according to Eq. (8) gives the correct $v^{2}$.

In Figs. 3 and $4,10 z$ of the particles are plotted. As the beam is compresed, an efficient use of the imulation grid i made by allowing the beam to expand in $r$ at fixed effective focusing forces while the opace-charge self-fielda increase to a dominant level, wo that the beam radiua alwost reaches the pipe radius.

In Summary, trangverae beam opread need not be an impediment to the longitudinal beas compresaion needed in heavg-ion fusion to increane peak power by 1 to 2 orders of magnitude. Additional work is nesessary to develop a complete understanding for a range of initial conditions. In particular, the parabolic beam line dengicy $\lambda(z, 0)$ introduced above (because of the existence of an analytical model For this profile) uge focusing force inefficiently; a nearly flat $\lambda(x, 0)$ is preferable in the rebard. Alao needed are additional atudies of multidimenoional effect introduced by beam mioalignmencs and by the accumulation of realistic jitters in acceleration forces. Effects of initial beam temperature in the langitudiral direction must $\Delta$ loo be introduced.
[1] A. Faltens, E. Hoyer, and D. Keefe, "A 3 Hegajoule Heavy-Ion Fusion Driver," in High Power Beams 81, H. J. Doucet and J. M. Buzzi, Edt., Ecole Polytechnique, Palnimeau, France, 1981, PP. 751-758.

12] $B$. 0 , Bangerter, "The U,S, Prograw in Jeavy-1on Fusion," Los Alawos National Laboratory, LOB Alamos, H. Mex., LA-UR-B2:1192 (1982).

(3) "A Proposed Program to Develop Liruear Induction Accelerator Technology in Support of the Natimal Accelerator Inertial Fuaion Plan," Laureace Berkeley Laboratory, Berkeley, Calif., LBL PUB-5065, 1982.

[4] J. Wrk. Mark et al., "Heavy-lon Inertial Fusion: Suggested Experiments on Disk Heating and Beam Transport Uaing Acceierator Test Facilities," in Hiih-Poider BeamB B1, H. J. Doucet and J. $H$. Buzzi, Eda., Ecole Polytechnique, Palaiseau, France, 1981, Pp. 649-656.

[5] J. W-K. Mark, "Recent U.S. Target Physics Related Regearch in Heavy Ion Furion," in Proc. Symp. on Accelerator ABpects of Heavy lon Fusion, D. Boehne, Ed., Gevellachaft fur Schverionen forechung, Darmstadt, $H$. Germany, GSI-82-8, 1982 .

(6) E. P. Lee and J. W-K. Mark, "Studies for the High Temperature Experiment in Heavy-Ion Fusion," Laser Program Annual Report 83, Lawrence Liverwore National Laboratory, Livermore, Calif., UCRL-50021-83, 1984, PP. 3-13 ro 3-21.

[7] A. Palevoky, "Generation of Intense Microwave Radiation by the Relativistic e-Eeam Magnetron (Experiment and Numerical Simulation)", Ph.D. thesis, Massachusetts Institute of Technology, Cambridge, Mes8., 1980.

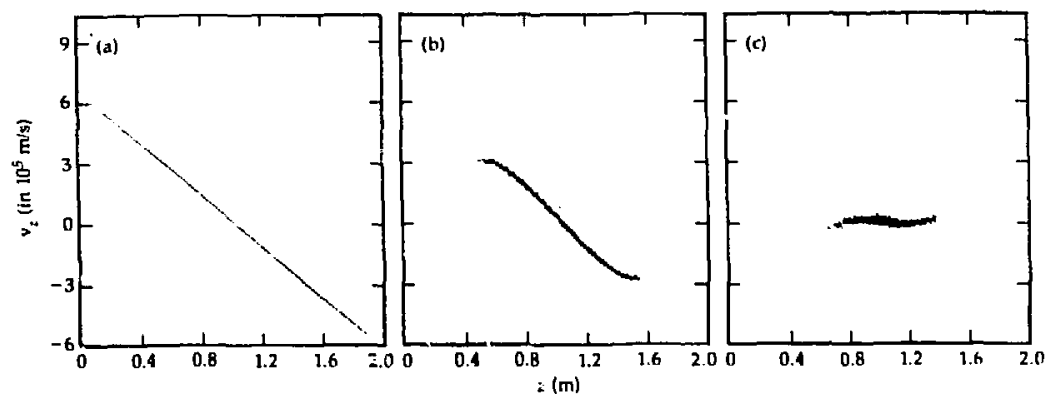

Fig. 3. The $\left(z, v_{z}\right)$ phase space of the 2-D particle-code sinulation (see (ext) at (a) $t$ o (initial velocity $t i l t),(b) t=0.7 \mu s,(c) t=1.4 \mu s$ (final compressed state).
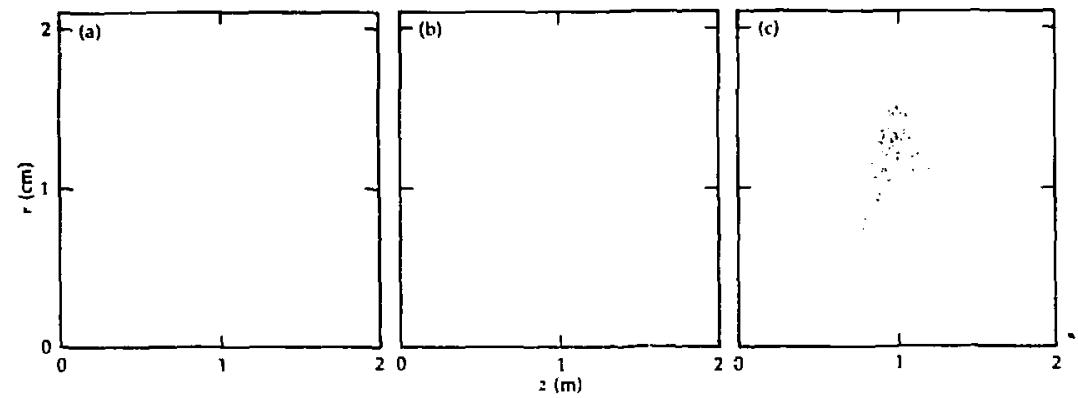

Fig. 4. The spatial positions in $(r, z)$ coordinates of $10 t$ of the particles in the 2-D imulation of Fig. 3, at corresponding times. Note the different torizontal and vertical length scalea. 


\section{DISCLAIMER}

This report was prepared as an account of work sponsored by an agency of the United States Government. Neither the United States Government nor any agency thereof, nor any of their employees, makes any warranty, express or implied, or assumes any legal liability or responsibility for the accuracy, completeness, or usefulness of any information, apparatus, product, or process disclosed, or represents that its use would not infringe privately owned rights. Reference herein to any specific commercial product, process, or service by trade name, trademark, manufacturer, or otherwise does not necessarily constitute or imply its endorsement, recommendation, or favoring by the United States Government or any ugency thereof. The views and opinions of authors expressed herein do not necessarily state or reflect those of the United States Government or any agency thereor. 